\title{
SIMULATION MODEL FOR PREDICTION OF TRANSIENT PERFORMANCE CHARACTERISTICS OF SINGLE-PHASE SHADED POLE MOTOR
}

\author{
Vasilija Sarac — Tatjana Atanasova-Pacemska *
}

\begin{abstract}
Paper proposes mathematical model of single phase shaded pole motor suitable for analysis of motor dynamic behavior. Derived mathematical model from $d-q$ reference frame theory is applied at motor simulation model. Derived simulation model enables analysis of transient performance characteristics of motor currents, speed and electromagnetic torque under different operating regimes. Obtained results from the simulation are compared with data from analytical calculations based on method of symmetrical components and data from experiment for the purpose of verification of the simulation model. Simulation model is useful for studying the effect of parameters on motor starting and running characteristics at different types of loads.

K e y w or d s: single-phase shaded pole motor, simulation model, transient performance characteristics
\end{abstract}

\section{INTRODUCTION}

Single-phase shaded pole motors are the most commonly used single phase motors because of their relatively simplicity, robust construction, and capabilities to withstand overloads during locked-rotor episodes when the motor current approaches the rated current. Although it may appear simple by design, the analysis of single phase shaded pole motor has been rendered nothing short of challenging because of the complexity of electromagnetic processes inside the machine as a result of the presence of two stator windings electromagnetically coupled with rotor winding which produce elliptical electromagnetic filed in the air gap of motor. Backwards rotating electromagnetic filed with relatively high amplitude is also present in motor air gap as well as high order space harmonics which contribute towards complexity of electromagnetic processes inside the motor. Consequently electromagnetic theory and equations valid for symmetrical three phase motors are inappropriate for calculation of parameters and characteristics of single phase shaded pole motor. Calculation of motor parameters and steady state performance characteristics is based on the method of symmetrical components and double-field revolving theory described with motor equivalent circuits [1-9]. Revolving filed theory is also used for determination forward and backward field torque [10]. Several papers investigated the influence of various motor design parameters on performance characteristics of the shaded pole motors and motor operation [11-13]. Numerical models of shaded pole motors have been constructed in order to determine the magnetic flux density distribution at crosssection of shaded pole motor [14-17]. During recent years, the increasing numbers of simulation models of different types of the motors have been developed mainly aimed for the simulation of motor transient behaviour during start up to the steady-state operation regime [18-25]. These simulation models have proven themselves as reliable replacement of laboratory equipment necessary for recording motor transient operation and obtaining different motor parameters such as: starting currents and torque as well as motor starting time under no load or with different types of loads. They are providing important data for coordination of motor electrical protection and complete coupling of the motor with the load into electromechanical drive system. Relatively few works are dedicated to the calculation of transient performance characteristics of single-phase shaded pole motor. Lock [26] introduced step-by-step method which was basically a transient analysis of the motor since the currents, torque and flux linkage were evaluated at each time step and set of differential equations which described machine behaviour was numerically solved. Oscheiba, Ahmed and Rahman [27] presented analysis for evaluation of performance characteristics of reluctance-augmented shaded pole motor at dynamic and steady-sate conditions. Recent versions of SIMULINK for MATLAB offer adequate models of single phase motors mainly capacitor-start, capacitor start and run motors as well as split phase single-phase motors that with small modification can be used for obtaining motor transient performance characteristics. Paper proposes mathematical model of single-phase shaded pole motor based on motor $d-q$ reference frame theory suitable for direct implementation in Simulink for Matlab $[28,29]$. Adequate set of ordinary differential equation of first order, which describe motor transient behavior, is derived, enabling obtaining of the transient performance characteristics of all motor currents, electromagnetic torque and flux linkages directly from the developed Simulink model. Since derived set of equation is time de-

\footnotetext{
* Faculty of Electrical Engineering, University Goce Delcev, P.O.Box 201, 2000 Stip, Macedonia, vasilija.sarac@ugd.edu.mk; tatjana.pacemska@ugd.edu.mk
} 


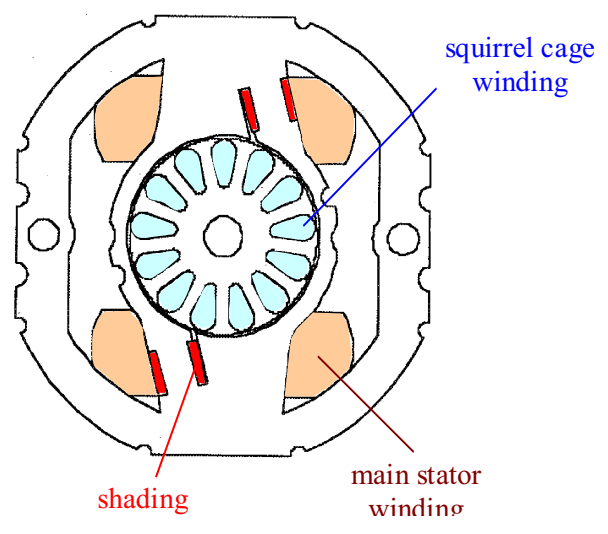

Fig. 1. Motor outer and inner view

pendant, their solution provides continuous monitoring of all typical motor variables for user specific defined time. Derived simulation model is suitable for application for all motor operating regimes: no-load, rated load and locked rotor. It can be easily adapted and used for arbitrary type of shaded pole motor with one shading coil per pole by inputting adequate motor parameters. Results are obtained quickly and easily due to Simulnik user-friendly interface and short simulation times. They are comprehensible for users since they are expressed SI units and refer to real motor currents in all windings, not the auxiliary $d-q$ currents from the mathematical model and consequently can be easily compared with the results from measurements. Transient performance characteristics of all important motor variables are obtained for no-load as well as for rated load, mining motor coupled with fan, and load characteristic of the fan is simulated as well. Derived model can be easily adapted for other types of loads as well. Obtained model is useful for studying the complete drive system during motor start up as well as during steady-state operation with respect to the motor starting time, starting current and effectiveness of the coupling of the motor with the load. Obtained results from the model are compared with data from the analytical calculation and from the measurements for the purpose of verification of the simulation model. Analysis is applied on motor type AKO-16, product of company MicronTech (Fig. 1) with rated data: voltage $U_{n}=220 \mathrm{~V}$, frequency $f_{n}=50 \mathrm{~Hz}$, input current $I_{1 n}=0.125 \mathrm{~A}$, pair of poles $2 p=24$, input power $P_{1 n}=18 \mathrm{~W}$, rated speed $n_{n}=2520 \mathrm{rpm}$. Experiments are done for three typical motor operating regimes: no-load, rated load and locked rotor. Motor main winding current, speed, input and output power as well as power factor are measured during different operating regimes and for different supply voltages. Measurements are repeated on four samples of the investigated type of the motor. Analyzed motor has wide application in numerous household devices such as fans and blowers. Therefore developed simulation model is useful for studying real time transient processes of this type of the motor coupled with the load especially in cases when there is a lack of the laboratory equipment for on-line recording of motor transient behavior. Further more, developed model gives an insight in the behavior of the currents in shading coil and rotor winding during start-up and steady-state operation, having on mind, that these variables can not be experimentally easily measured due to the motor construction.

\section{METHODOLOGY AND SIMULATION MODEL}

Derivation of motor model in Simulink is based on the mathematical model suitable for obtaining motor transient performance characteristics of speed, electromagnetic torque, all motor currents as well as flux linkages. Therefore, all stator and rotor variables are transformed into arbitrary rotating $d, q$ reference frame. Transformation of arbitrary variable $-f$ associated to the stator circuit is [29]

$$
\begin{gathered}
\boldsymbol{f}_{q d s}=\mathbf{K}_{2 s} \boldsymbol{f}_{a b s}, \\
\boldsymbol{f}_{q d s}=\left[\begin{array}{ll}
f_{q s} & f_{d s}
\end{array}\right]^{\top}, \quad\left(\boldsymbol{f}_{a b s}\right)^{\top}=\left[\begin{array}{ll}
f_{a s} & f_{b s}
\end{array}\right] .
\end{gathered}
$$

Transformation matrix is

$$
\mathbf{K}_{2 s}=\left[\begin{array}{cc}
\cos \theta & \sin \theta \\
\sin \theta & -\cos \theta
\end{array}\right]
$$

where $\theta=\int \omega \mathrm{d} t$ is the angular displacement between two-phase $a, b$ system and $d, q$ system while $\omega$ is the angular speed. Index " $s$ " is associated to the stator variables. In this case of shaded pole motor transformation is performed into stationary $d-q$ reference frame by replacing $\omega=0$.

For the rotor circuit following equation is valid [29]

$$
\begin{gathered}
\boldsymbol{F}_{q d r}=\mathbf{K}_{2 r} \boldsymbol{f}_{a b r}, \\
\left(\boldsymbol{f}_{q d r}\right)^{\top}=\left[\begin{array}{ll}
f_{q r} & f_{d r}
\end{array}\right], \quad\left(\boldsymbol{f}_{a b r}\right)^{\top}=\left[\begin{array}{ll}
f_{a r} & f_{b r}
\end{array}\right], \\
\mathbf{K}_{2 r}=\left[\begin{array}{cc}
\cos \beta & \sin \beta \\
\sin \beta & -\cos \beta
\end{array}\right],
\end{gathered}
$$

$\beta=\theta-\theta_{r}, \theta_{r}=\int \omega_{r} \mathrm{~d} t$ is the rotor angular displacement and $\omega_{r}$ is the rotor angular speed.

According to generalized formulation of equation (1) power supply of the motor or voltages of stator windings transformed into stationary $d-q$ reference systems can be written as

$$
\begin{aligned}
& u_{q s}=u_{a s} \cos \theta+u_{b s} \sin \theta, \\
& u_{d s}=u_{a s} \cos \theta-u_{b s} \sin \theta .
\end{aligned}
$$

Equations that describe motor transient behaviour are

$$
\begin{aligned}
& u_{q s}=r_{q s} i_{q s}+\frac{\mathrm{d} \lambda_{q s}}{\mathrm{~d} t}, \\
& u_{d s}=r_{d s}^{\prime} i_{d s}+\frac{\mathrm{d} \lambda_{d s}^{\prime}}{\mathrm{d} t}, \\
& u_{q r}^{\prime}=r_{r}^{\prime} i_{q r}^{s}-\lambda_{d r}^{\prime s} \omega_{r}+\frac{\mathrm{d} \lambda_{q r}^{\prime s}}{\mathrm{~d} t}, \\
& u_{d r}^{\prime s}=r_{r}^{\prime} i_{d r}^{\prime s}+\lambda_{q r}^{\prime s} \omega_{r}+\frac{\mathrm{d} \lambda_{d r}^{\prime s}}{\mathrm{~d} t} .
\end{aligned}
$$


where $\omega_{r}$ is the rotor angular speed.

Stator and rotor flux linkages in $d-q$ system are represented by

$$
\begin{aligned}
& \lambda_{q s}=L_{l q s} i_{q s}+L_{m q}\left(i_{q s}+i_{q r}^{\prime s}\right), \\
& \lambda_{d s}=L_{l d s}^{\prime} i_{d s}+L_{m q}\left(i_{d s}+i_{d r}^{\prime s}\right), \\
& \lambda_{q r}^{\prime s}=L_{l r}^{\prime} i_{q r}^{\prime s}+L_{m q}\left(i_{q s}+i_{q r}^{\prime s}\right) \\
& \lambda_{d r}^{\prime s}=L_{l r}^{\prime} i_{d r}^{\prime s}+L_{m q}\left(i_{d s}+i_{d r}^{\prime s}\right),
\end{aligned}
$$

where $r_{q s}, r_{d s}^{\prime}$ and $r_{r}^{\prime}$ are resistance of the main and the auxiliary stator winding (shading coil) and the rotor winding respectively. Parameters of the auxiliary stator winding and the rotor winding are referred to the main stator winding.

$L_{l q s}, L_{l d s}^{\prime}$ and $L_{l r}^{\prime}$ are inductances of the main and the auxiliary stator winding and the rotor winding respectively. $L_{m q}$ is the mutual inductance between stator and rotor windings. Taking into consideration that the rotor winding is of squirrel cage type, consequently it is short circuited, than $u_{q r}=0$ and $u_{d r}=0$. By replacing the (11) into (10) following set of equations is obtained

$$
\begin{aligned}
u_{q s} & =i_{q s} r_{q s}+\frac{\mathrm{d}}{\mathrm{d} t}\left[L_{l q s} i_{q s}+L_{m q}\left(i_{q s}+i_{q r}^{\prime s}\right)\right], \\
u_{d s} & =i_{d s} r_{d s}^{\prime}+\frac{\mathrm{d}}{\mathrm{d} t}\left[L_{l d s}^{\prime} i_{d s}+L_{m q}\left(i_{d s}+i_{d r}^{\prime s}\right)\right] . \\
0 & =r_{r}^{\prime} i_{q r}^{s}-\omega_{r}\left[L_{l r}^{\prime} i_{d r}^{\prime s}+L_{m q}\left(i_{d s}+i_{d r}^{\prime s}\right)\right] \\
& +\frac{\mathrm{d}}{\mathrm{d} t}\left[L_{l r}^{\prime} i_{q r}^{\prime s}+L_{m q}\left(i_{q s}+i_{q r}^{\prime s}\right)\right] \\
0 & =r_{r}^{\prime} i_{d r}^{\prime s}+\omega_{r}\left[L_{l r}^{\prime} i_{q r}^{\prime s}+L_{m q}\left(i_{q s}+i_{q r}^{\prime s}\right)\right] \\
& +\frac{\mathrm{d}}{\mathrm{d} t}\left[L_{l r}^{\prime} i_{d r}^{\prime s}+L_{m q}\left(i_{d s}+i_{d r}^{\prime s}\right)\right] .
\end{aligned}
$$

By integrating (12) over the time and its rearranging set of equation is obtained suitable for implementation into the simulation model and for calculation of motor transient characteristics.

$$
\begin{aligned}
i_{q s} & =\frac{1}{L_{l q s}+L_{m q}} \int_{0}^{t} u_{q s} \mathrm{~d} t-\frac{r_{q s}}{L_{l q s}+L_{m q}} \int_{0}^{t} i_{q s} \mathrm{~d} t \\
& -\frac{L_{m q}}{L_{l q s}+L_{m q}} i_{q r}^{\prime s}, \\
i_{d s} & =\frac{1}{L_{l d s}^{\prime}+L_{m q}} \int_{0}^{t} u_{d s} \mathrm{~d} t-\frac{r_{d s}^{\prime}}{L_{l d s}^{\prime}+L_{m q}} \int_{0}^{t} i_{d s} \mathrm{~d} t \\
& -\frac{L_{m q}}{{ }^{\prime} L_{l d s}+L_{m q}} i_{d r}^{\prime s}, \\
i_{q r}^{\prime s} & =\omega_{r} \int_{0}^{t} i_{d r}^{\prime s} \mathrm{~d} t+\frac{\omega_{r} L_{m q}}{L_{l r}^{\prime}+L_{m q}} \int_{0}^{t} i_{d s} \mathrm{~d} t \\
& -\frac{r_{r}^{\prime}}{L_{l r}^{\prime}+L_{m q}} \int_{0}^{t} i_{q r}^{\prime s} \mathrm{~d} t-\frac{L_{m q}}{L_{l r}^{\prime}+L_{m q}} i_{q s}, \\
i_{d r}^{\prime s} & =-\omega_{r} \int_{0}^{t} i_{q r}^{\prime s} \mathrm{~d} t-\frac{\omega_{r} L_{m q}}{L_{l r}^{\prime}+L_{m q}} \int_{0}^{t} i_{q s} \mathrm{~d} t \\
& -\frac{r_{r}^{\prime}}{L_{l r}^{\prime}+L_{m q}} \int_{0}^{t} i_{d r}^{\prime s} \mathrm{~d} t-\frac{L_{m q}}{L_{l r}^{\prime}+L_{m q}} i_{d s} .
\end{aligned}
$$

Fifth equation which describes the motor transient behaviour is the equation of electromagnetic torque

$$
M_{e m}=J \frac{2}{P} \frac{\mathrm{d} \omega_{r}}{\mathrm{~d} t}+M_{s}
$$

necessary for obtaining the motor angular speed. $J$ is the moment of inertia of the motor, $M_{s}$ is the load torque and $P$ is the number of machine poles.

On the other hand, electromagnetic torque can be expressed via electrical parameters as

$$
M_{e m}=\frac{P}{2} L_{m q}\left(i_{d r}^{\prime s} i_{q s}-i_{q r}^{\prime s} i_{d s}\right) .
$$

From (14) and (15), equation of motor angular speed is derived:

$$
\frac{\mathrm{d} \omega_{r}}{\mathrm{~d} t}=\frac{P^{2} L_{m q}}{4 J}\left(i_{d r}^{\prime s} i_{q s}-i_{q r}^{\prime s} i_{d s}\right)-\frac{P}{2 J} M_{s}
$$

By integrating (16) and considering (13) complete set of equations is derived suitable for implementation into simulation model.

$$
\begin{aligned}
\omega_{r}=\frac{P^{2} L_{m q}}{4 J} \int_{0}^{t} i_{d r}^{\prime s} i_{q s} \mathrm{~d} t- & \\
& \frac{P^{2} L_{m q}}{4 J} \int_{0}^{t} i_{q r}^{\prime s} i_{d s} \mathrm{~d} t-\int_{0}^{t} \frac{P}{2 J} M_{s} \mathrm{~d} t .
\end{aligned}
$$

Block diagram of motor simulation model is presented in Fig. 2. It is consisted of four main parts: two-phase voltage supply of the motor, transformation of supply voltages from two phase system of voltages into stationary $d, q$ reference system, mathematical model of the motor which gives as direct outputs motor angular speed- $\omega_{r}$ and electromagnetic torque- $M_{e m}$. Currents in main stator winding- $i_{1}$, shading coil- $i_{3}$ and rotor winding- $i_{2}$ are obtained after inverse transformation from $d, q$ system into $a, b$ (two phase) system.

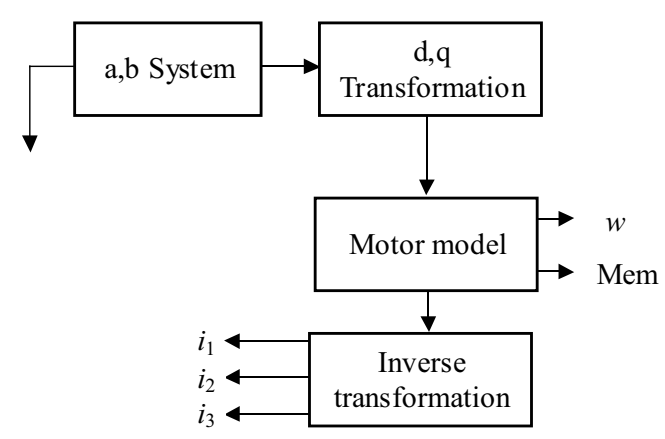

Fig. 2. Block diagram of motor simulation model 


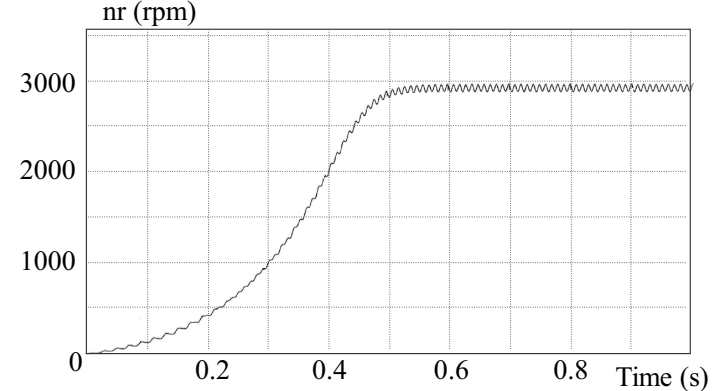

(a)

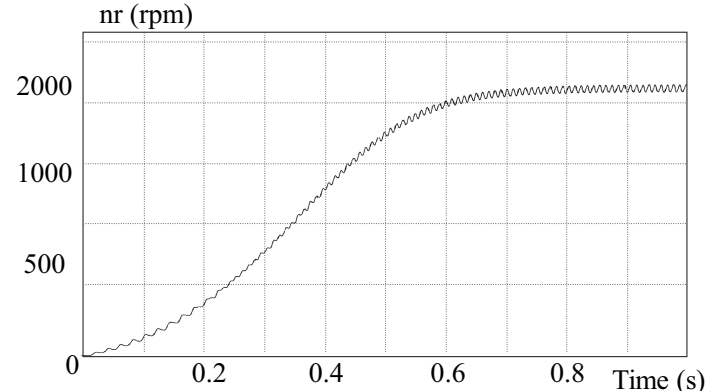

(b)

Fig. 3. Transient characteristic of speed (a) - no-load, (b) - rated load
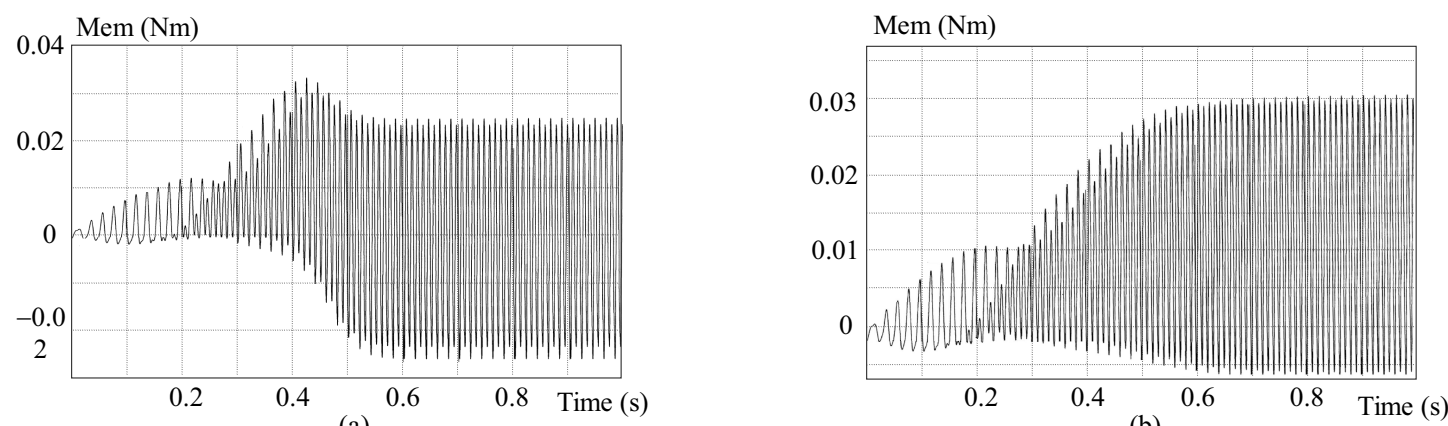

(b)

Fig. 4. Transient characteristic of torque (a) - no-load, (b) - rated load
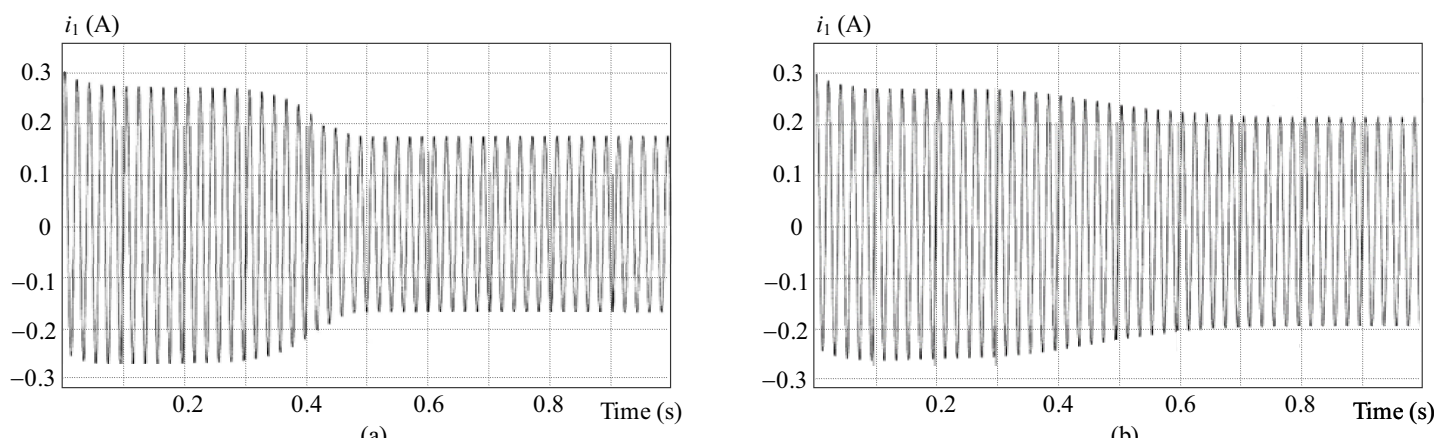

Fig. 5. Transient characteristic of main winding current (a) - no-load, (b) - rated load
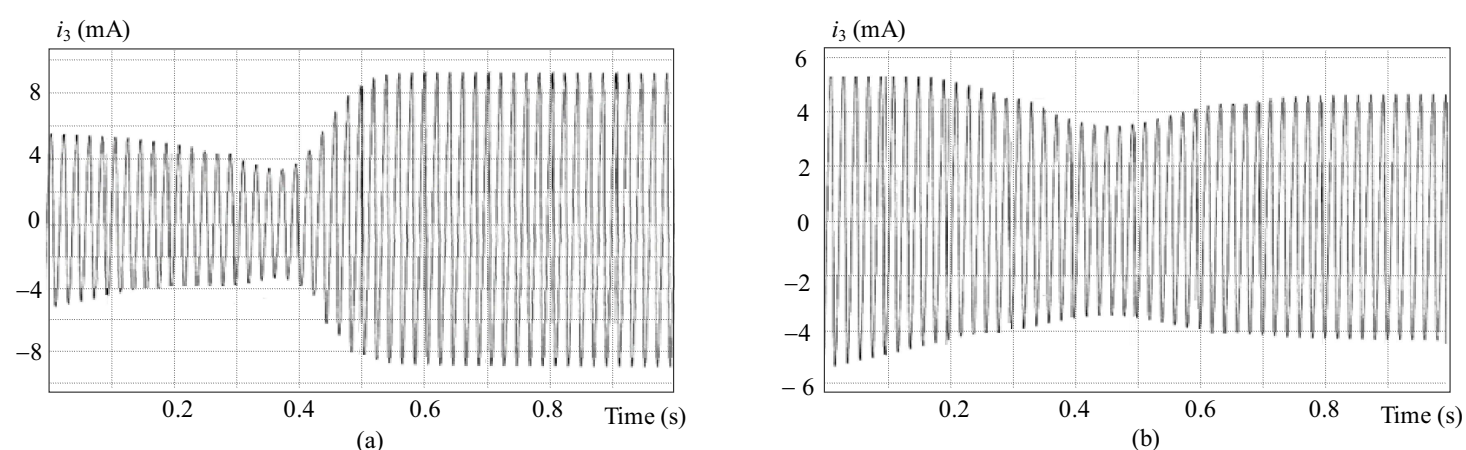

Fig. 6. Transient characteristic of shading coil current (a) — no-load, (b) — rated load
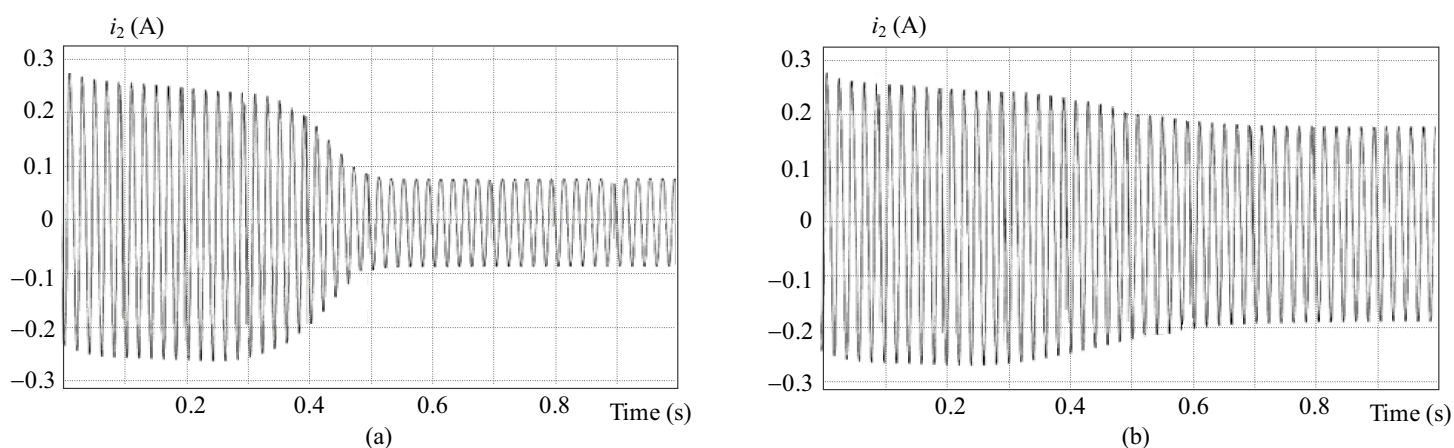

Fig. 7. Transient characteristic of rotor winding current (a) - no-load, (b) - rated load 


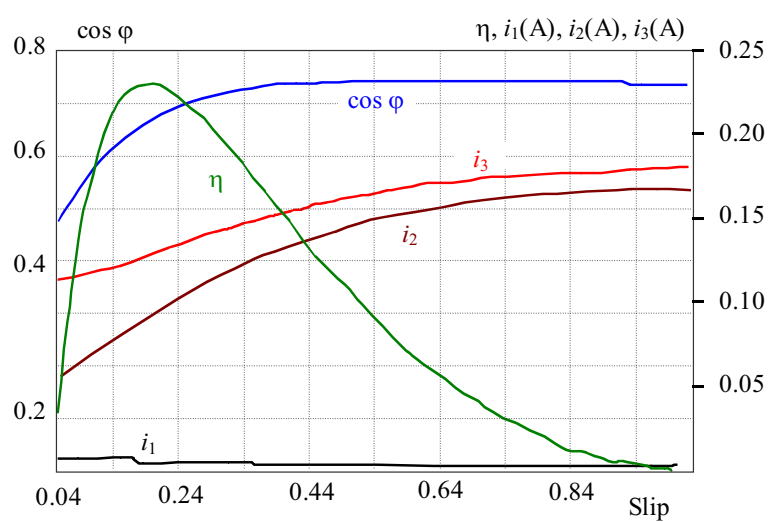

Fig. 8. Steady-state characteristics of motor currents efficiency and power factor

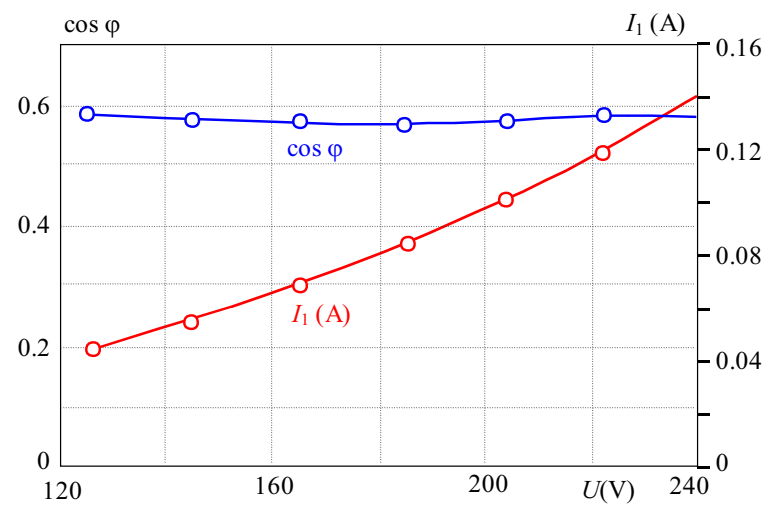

Fig. 10. No-load characteristics of main winding current and power factor from experiment

\section{RESULTS}

\section{Results from simulation model}

Execution of the simulation results with the motor transient performance characteristics of speed $n_{r}=f(t)$, electromagnetic torque $M_{e m}=f(t)$, current in the main stator winding $i_{1}=f(t)$, in the shading coil $i_{3}=f(t)$ and the rotor winding $i_{2}=f(t)$. Matrix of the inverse transformation is identical with the matrix of the direct transformation for the stator and rotor circuit as well.

$$
\begin{aligned}
& \mathbf{K}_{2 s}=\mathbf{K}_{2 s}^{-1}, \\
& \mathbf{K}_{2 r}=\mathbf{K}_{2 r}^{-1},
\end{aligned}
$$

Currents in all three windings are obtained after the inverse transformation

$$
\begin{aligned}
& i_{1}=i_{q s} \cos \theta+i_{d s} \sin \theta, \\
& i_{3}=i_{q s} \sin \theta+i_{d s} \cos \theta, \\
& i_{2}=i_{q r} \cos \beta+i_{d r} \sin \beta .
\end{aligned}
$$

Simulation is performed for two different operating regimes: acceleration at no-load meaning motor slip $s=$ 0.04 and acceleration at rated load or motor slip $s=0.16$. Since this type of the motor is aimed for fan application

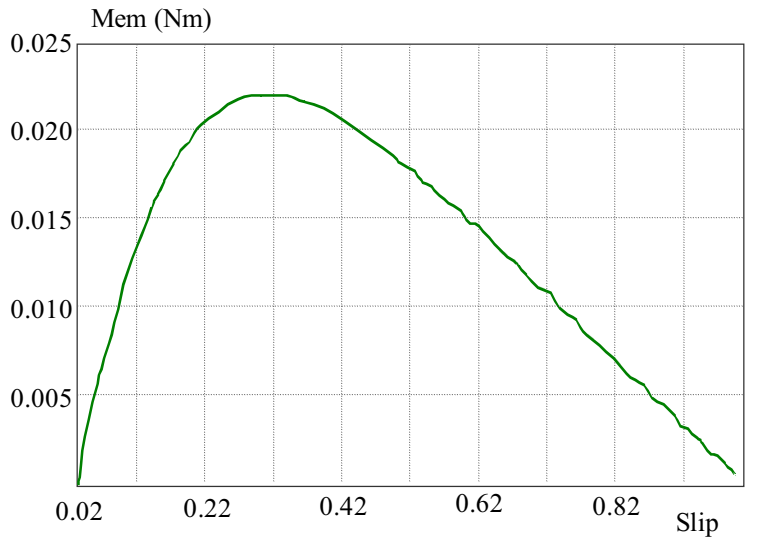

Fig. 9. Steady-state characteristics of electromagnetic torque

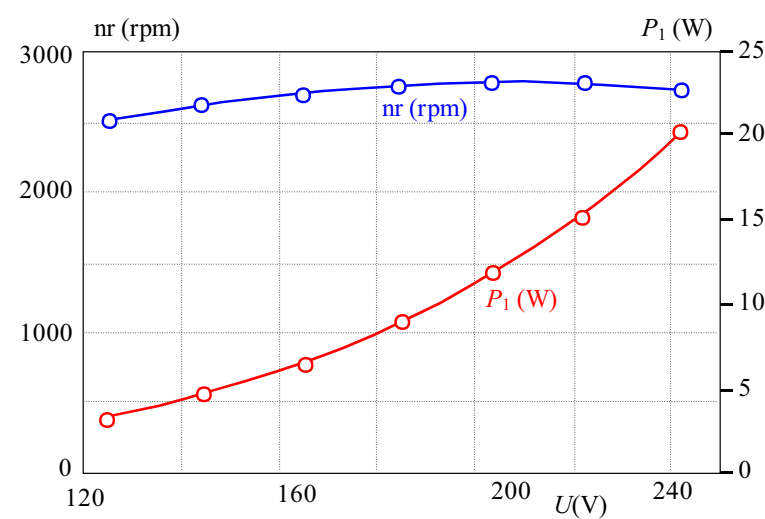

Fig. 11. No-load characteristics of speed and input power from experiment

in the motor model is inserted load torque $M_{s}=k n_{r}^{2}$. Constant $k$ is specified from cross-section point of motor mechanical characteristic $M_{e m}=f(s)$ and load characteristic at rated load.

In Figs. 3 and 4 are presented transient characteristics of speed and electromagnetic torque for no-load and rated load.

Characteristic of torque has the fundamental frequency torque in the initial region, increasing magnitude of double frequency pulsating torque, region of the maximum torque with large average and pulsating torques and steady-state region with zero average torque but a large double frequency torque [26]. In Figs. 5, 6 and 7 currents in main, auxiliary and rotor winding are presented.

\section{Results from analytical calculations and experi- ment}

Equivalent circuits and method of symmetrical components are used for calculation of steady-state performance characteristics of the motor. As output results are obtained all motor currents, electromagnetic torque, power factor and efficiency for different motor speeds ie motor slips. In Fig. 8 are presented characteristics of main- $I_{1}$, auxiliary $I_{3}$ and rotor winding current $I_{2}$ calculated on the base of the method of symmetrical components for 


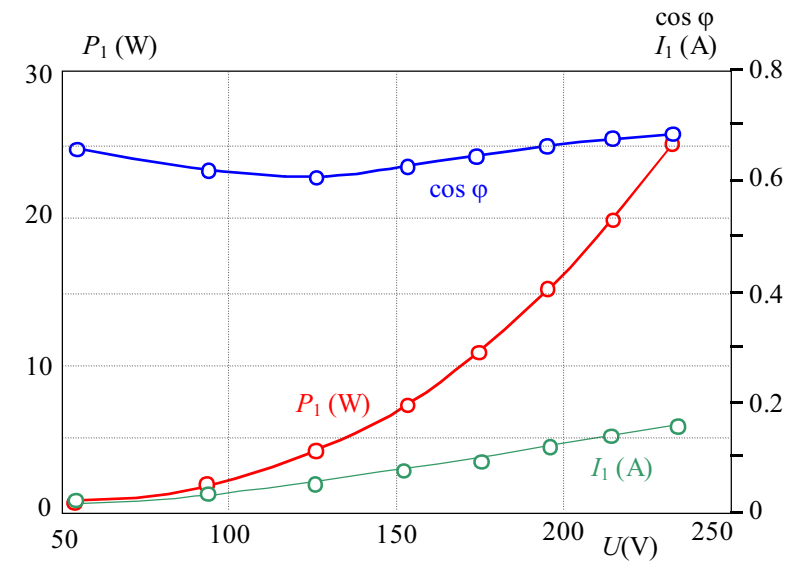

Fig. 12. Locked rotor characteristics of main winding current, input power and power factor

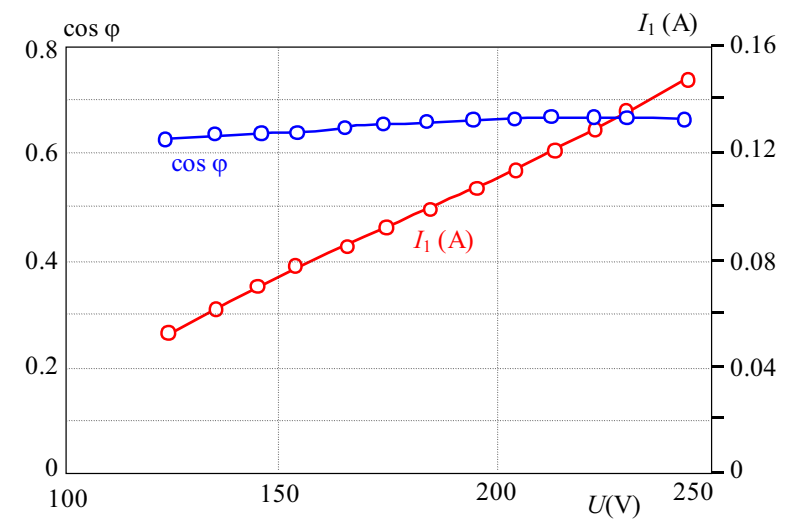

Fig. 13. Characteristics of power factor and current in main stator winding at rated load

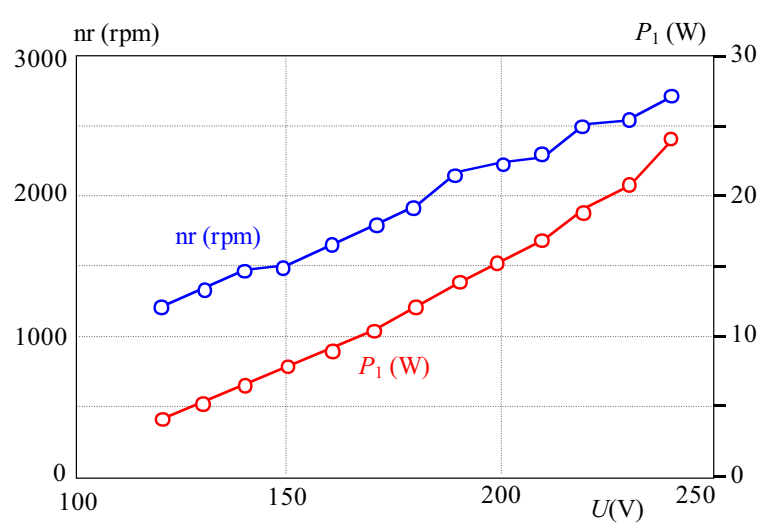

Fig. 14. Characteristics of speed and input power at rated load

different motor slips as well as efficiency factor $\eta$ and power factor $\cos \varphi$. Steady-state characteristic of electromagnetic torque is calculated as well, and in Fig. 9 it is presented.

Series of measurements are done on four samples of the analyzed type of motor. Three typical operating regimes are examined: no-load, rated load and locked rotor. On the base of measured data, characteristics of no-load, rated-load and locked rotor are obtained for different supply voltages. In Figs. 10 and 11 data from experiment in case of no-load operation or motor slip of 0.04 are presented.

In Fig. 12 are presented characteristics for locked-rotor operating regime or motor $\operatorname{sip} s=1$

In Figs. 13 and 14 experimental data of power factor, current in main stator winding, speed and input power for rated load operation or motor slip $s=0.16$ are presented

\section{DISCUSSION OF RESULTS AND THEIR COMPARISON}

From presented results, it is evident that motor reaches the speed of $2900 \mathrm{rpm}$ during no-load acceleration (Fig. 3a). Obtained result is compared with the one from the experiment during which motor obtains speed of $2820 \mathrm{rpm}$ for rated voltage $220 \mathrm{~V}$ (Fig. 11). In case of rated load operation in simulation model (Fig. 3b), motor reaches the speed of $2200 \mathrm{rpm}$, result that is close enough to the measured speed of $2520 \mathrm{rpm}$ (Fig. 14). As expected, acceleration time is shorter in case of no-load compared to rated load operating regime which is evident from presented transient characteristics of speed in Fig. 3.

Current in main stator winding under no-load and rated load operation has a maximal value of the starting current of $0.275 \mathrm{~A}$, or rms value of $0.195 \mathrm{~A}$ (Fig. 5). Rms value of the starting current from the simulation model is compared with the data from the analytical calculations and corresponding steady-state characteristic (Fig. 8) . Starting current from the steady-state characteristic is 0.181 A (Fig. 8), for the motor slip of 0.99 . Further more the obtained starting current from the simulation model is compared with the measured current of $0.15 \mathrm{~A}$ for $220 \mathrm{~V}$ (Fig. 12). This proves the satisfactory agreement of measurements with the simulation model and the analytical calculation. After $0.5 \mathrm{~s}$ at no-load operation, motor is reaching the final speed and consequently the current in the main winding is decreasing from the value of the starting current up the value of no-load current which from simulation is $0.175 \mathrm{~A}$ - maximal current or rms current of $0.124 \mathrm{~A}$ (Fig. 5a). Value of the no-load current from simulation is in a good agreement with the data from the experiment - 0.12 A for $220 \mathrm{~V}$ (Fig. 10) and from the calculation - 0.113 A for motor slip of 0.04 (Fig. 8). Under rated load operation, after $0.6 \mathrm{~s}$, motor has finished the acceleration and consequently the current in the main winding is decreasing up to the rated current, which from simulation is $0.14 \mathrm{~A}-\mathrm{rms}$ (Fig. 5b). This value is compared with the value of the rated current from the experiment $0.125 \mathrm{~A}$ (Fig. 13) and from the calculation 0.1259 A for the rated slip-s of 0.16 (Fig. 8).

Current in the auxiliary stator winding at no-load operation after motor has finished the acceleration is reaching the rms value of $0.0063 \mathrm{~A}$ (Fig. 6a), which is in a good agreement with the value from the analytical calculation - 0.007 A for motor slip 0.04 (Fig. 8). For rated load operating condition, $s=0.16$, current in the auxiliary winding is reaching the final rms value of $0.003 \mathrm{~A}$ 
Table 1. Comparison of simulated, analytical and experimental results at no-load, slip $s=0.04$

\begin{tabular}{ccccccc}
\hline & \multicolumn{3}{c}{ start up } & \multicolumn{3}{c}{ steady-state } \\
\cline { 2 - 7 } & simulation & $\begin{array}{c}\text { analytical } \\
\text { calculation }\end{array}$ & experiment & simulation & $\begin{array}{c}\text { analytical } \\
\text { calculation }\end{array}$ & experiment \\
\hline$I_{1}(\mathrm{~A})$ & 0.195 & 0.181 & 0.15 & 0.124 & 0.113 & 0.111 \\
$I_{2}(\mathrm{~A})$ & 0.162 & 0.167 & - & 0.056 & 0.05757 & - \\
$I_{3}(\mathrm{~A})$ & 0.0035 & 0.0039 & - & 0.0063 & 0.007 & - \\
$n_{r}(\mathrm{rpm})$ & - & - & - & 2820 & - & 2900 \\
\hline
\end{tabular}

Table 2. Comparison of simulated, analytical and experimental results at rated load, slip $s=0.16$

\begin{tabular}{ccccccc}
\hline & \multicolumn{3}{c}{ start up } & \multicolumn{3}{c}{ steady-state } \\
\cline { 2 - 7 } & simulation & $\begin{array}{c}\text { analytical } \\
\text { calculation }\end{array}$ & experiment & simulation & $\begin{array}{c}\text { analytical } \\
\text { calculation }\end{array}$ & experiment \\
\hline$I_{1}(\mathrm{~A})$ & 0.195 & 0.181 & 0.15 & 0.14 & 0.1259 & 0.125 \\
$I_{2}(\mathrm{~A})$ & 0.162 & 0.167 & - & 0.056 & 0.05757 & - \\
$I_{3}(\mathrm{~A})$ & 0.0035 & 0.0039 & - & 0.003 & 0.045 & - \\
$n_{r}(\mathrm{rpm})$ & - & - & - & 2200 & - & 2520 \\
\hline
\end{tabular}

(Fig. 6b) . From calculation it is 0.0045 A (Fig. 8) for value of the slip 0.16. Starting current in the auxiliary stator winding has the rms value of $0.0035 \mathrm{~A}$ from the simulation and 0.0039 A from the calculation (Fig. 8) for $s=0.99$.

Current in the rotor winding has the starting maximal value of $0.23 \mathrm{~A}$ or $\mathrm{rms}$ value of $0.162 \mathrm{~A}$ (Fig. 7). This result is compared with the result from the analytical calculation and according to Fig. 8 value of the rotor winding starting current is $0.167 \mathrm{~A}$ for the corresponding slip 0.99. After motor acceleration has finished this current is reaching the rms value of $0.056 \mathrm{~A}$ (Fig. 7a) which is in good agreement with data from calculation $0.05757 \mathrm{~A}$ in case of the no-load operation (Fig. 8) or $s=0.04$. In case of the rated load, after acceleration has finished current in rotor winding is obtaining the rms value of $0.12 \mathrm{~A}$ (Fig. 7b) while according to the calculations this current is $0.09 \mathrm{~A}$ (Fig. 8) for corresponding slip $s=0.16$.

In Tables 1 and 2 is presented comparison of obtained rms values of motor characteristics from simulation model, analytical calculation and experiment for no-load and rated load respectively. Presented results are related to the motor start-up and the steady-state operation.

Presented simulation model has been proved accurate enough for recording motor dynamic behavior during starting and running operating conditions at different loads. Motor acceleration time can be recorded as well as starting current, which enables precise prediction of motor behavior when it is accelerated at no-load or with different types of loads. This gives a useful insight in a complete drive system and the effectiveness of the coupling of the motor with the load. Analyzed motor is aimed for fan application or it is not aimed for hard starting conditions. Developed simulation model can be easily adapted to any type of single-phase shaded pole motor with arbitrary type of load by adequate replacing of motor parameters and load constant, which enables more extensive analysis of the different starting conditions of the motor to be done.

\section{CONCLUSION}

Paper proposes methodology and mathematical model, which enables obtaining of transient performance characteristics of the shaded pole motor such as: currents in all three motor windings, rotor speed and electromagnetic torque. The derived mathematical model is based on $d-q$ reference frame theory applied on this specific case of single-phase shaded pole motor with one shading coil per pole. Previously calculated motor parameters are implemented in the model as well. Set of five differential equation of first order that describe motor dynamic behavior is solved in Simulink for different operating regimes-no load and rated load. For the purpose of motor model verification, the obtained results are compared with the data from the analytical calculation based on the method of symmetrical components and double field revolving theory, which enables motor steady state performance characteristics to be obtained. Further verification of the developed simulation model is done by comparison of the obtained simulation data with the data from the measurements. They show reasonable agreement. Developed mathematical model can be easily applied on any type of the single-phase shaded pole motor with one shading coil per pole with the adequate replacing of the motor specific parameters. Accuracy of the developed model is highly dependant on the accurate calculation of the motor parameters. Therefore, further authors' research will be focused on calculation of the inductances by the aid of the numerical methods which should improve accuracy of the parameters and consequently of the whole simulation model. 


\section{Acknowledgment}

The authors are supported by the project Functional Spaces, Topological and Statistical Aspects and their Application in Electrical Engineering financed by University "Goce Delcev", Stip.

\section{REFERENCES}

[1] YEADON, W. H.-YEADON, A. W. : Handbook of small electric motors, McGraww-Hill,, 6-1-6-45, New York 2003.

[2] BOLDEA, I.-NASAR, S. A.: The Induction Machines Design Handbook, CRC Press, pp. 791-811, 2010.

[3] DAVIDSON, I. E.: Performance Calculation of a Shaded-Pole Single Sided Linear Induction Motor Using Symmetrical Components and Finite Element Method, Journal Electromotion 4 No. 4 (1997), 139-145.

[4] TRICKEY, P. H. : Performance Calculations of Shaded Pole Motors, AIEE Transactions 66 (1947), 1431-1438.

[5] CHANG, S. S. L.: Equivalent Circuits and Their Applications in Designing Shaded Pole Motors, AIEE Transactions 70 (1951), 690-699.

[6] TRUTT, F. C.: Equivalent Circuit Analysis of Shaded-Poles Motors, Electric Machines \& Electromechnics 6 (1981), 35-43.

[7] NONDAHL, T. A. : Equivalent Circuit Model for a Shaded-Pole Induction Motor, IEEE Transactions on Power Apparatus and Systems PAS-100 No. 1 (January 1981).

[8] MAKOWSKI, K.: Determination of performance characteristics of single-phase shaded pole induction motor by circuit field method, Electrical Engineering 84 No. 5 (2002), 281-286.

[9] DAVIDSON, I.-GIERAS, J. F.: Performance analysis of a shaded-pole linear induction motor using symmetrical components, field analysis, and finite element method, IEEE Transaction on Energy Conversion, 15 No. 1 (2000), 24-29.

[10] TAKANO, H. : Experimental Determination of the Forward and Backward Field Torque in Shaded Pole Motor, IEEE Transactions on Energy Conversion 4 No. 2 (1989), 257-263.

[11] BUTLER, O. I.-WALlaCE, A. K.: Generalised Theory of Induction Motors with Asymmetrical Primary Windings, Proc. IEE 125 No. 9 (September 1978), 831-834.

[12] MAKOWSKI, K.-SCHOEPP, K. : An Analysis of Shaded Pole Induction Motors with Increased Starting Torque, Electric Machines \& Power Systems 8 (1983), 419-432.

[13] PERRET, R.-POLOUJAdOFF, M. : Characteristics Analysis of Saturated Pole Induction Motors, IEEE Transaction of Power Apparatus and Systems PAS-95 No. 4 (July/August 1976), 1347-1352.

[14] AKBABA, M. Fakhro,-S. Q. : Field Distribution and Iron Loss Computation in Reluctance Augmented Shaded-Pole Motors Using Finite Element Method, IEEE Transactions on Energy Conversion 7 No. 2 (1992), 302-307.

[15] ANDRIOLO, M.-DEBORTOLI, M.-MARTINELI, G. MORINI, A. : Design Improvement of a Single-Phase Brushless Permanent Magnet Motor for Small Fan Appliances, IEEE Transactions on Industrial Electronics 57 No. 1 (2010), 85-95.

[16] PESSINA, G.-MORRA, E.: Optimization and design of the shaded pole single phase asynchronous motor, International symposium power electronics, electrical drives, automation and motion, SPEEDAM (2012), 469-473.
[17] DEGERSAM, H.-HAMAYER, K. : Time Harmonic Finite Element Simulation of a Shaded-Pole Induction Machine, Electromagnetic Fields in Electrical Engineering, 48-51 IOE Press, 2002.

18] MAKOWSKI, K.-WILK, M. J.: Determination of dynamic characteristics of the single-phase capacitor induction motor, Prezglad Electrotechniczny 87 No. 5 (2011), 231-237.

[19] MAKOWSKI, K.-WILK, M. J.: Experimental verification of field-circuit model of a single-phase capacitor induction motor, Prezglad Electrotechniczny 88 No. 7b (2012), 116-118.

[20] KHADER, S. H. : Modeling and simulation of single phase double capacitors induction motor Proceedings of the 2nd WSEAS International Conference on biomedical electronics and biomedical informatics, Moscow, Russia.

[21] JUNG, D-S.-LIM, S-B.-LEE, J-H.-LEE, S-H.-LIM, H-B. - KIM, Y-H. - LEE, J. : A Study on the Design and the Characteristics in Single-phase Line-start Permanent Magnet Motor, Proceeding of International Conference on Electrical Machines and Systems Seoul, Korea, (2007), 878-881.

[22] KISHORE, A.-PRASAD, R. C.-KARAN, B. M. : MATLAB SIMULINK Based DQ Modeling and Dynamic Characteristics of Three Phase Self Excited Induction Generator, Progress In Electromagnetics Research Symposium, Cambridge, USA (2006), 312-316.

[23] PAHWA, V.-SANDHU, K. S.: Transient analysis of three phase induction machine using different reference frames, APRN Journal of Engineering and Applied Sciences 4 No. 8 (2009), 31-38.

[24] DESPOTOVIČ, Ž.- ŠINIK. V.: The simulation and experimental results of dynamic behavior of torque motor having permanent magnets, Journal of Electrical Engineering 66 No. 2 (2015), 97-102

[25] CAI, J.-DENG, Z.: Offline and online modeling of switched reluctance motor based on RBF neural networks, Journal of Electrical Engineering 64 No. 3 (2013), 186-190.

[26] LOCK, K. S. : "Transient Analysis of the Shaded-Pole Motor by Numerical solution of the Basic Performance Equations, IEEE Transactions on Power Apparatus and Systems, PAS-103 No. 9 (September 1984), 2691-2698.

[27] OSheiBA, A. M.-AHMED, K. A.-RAhMAN, M. A.: "Performance Prediction of Shaded Pole Induction Motors, IEEE Transactions on Industry Applications 27 No. 5 (September/October 1991), 876-882.

28] ONG, CH-M. : Dynamic Simulation of Electric Machinery using Matlab/Simulink, Prentice Hall PTR, (1998), 216-219.

[29] KRAUSE, P. C.-WASYNCZUK, O.-SUDHOFF, S. D. : Analysis of Electric Machinery, book, IEEE Press, New York, USA (1995), 415-418.

Received 18 January 2016

Vasilija Sarac, associate professor of the Faculty of Electrical Engineering at University Goce Delcev, Stip, Republic of Macedonia. Her main research interests include the design, simulation and optimization methods in electrical machines and power converters.

Tatjana Atanasova-Pacemska, associate professor of the Faculty of Electrical Engineering at University Goce Delcev, Stip, Republic of Macedonia. Her research field is applied mathematical methods in engineering. 